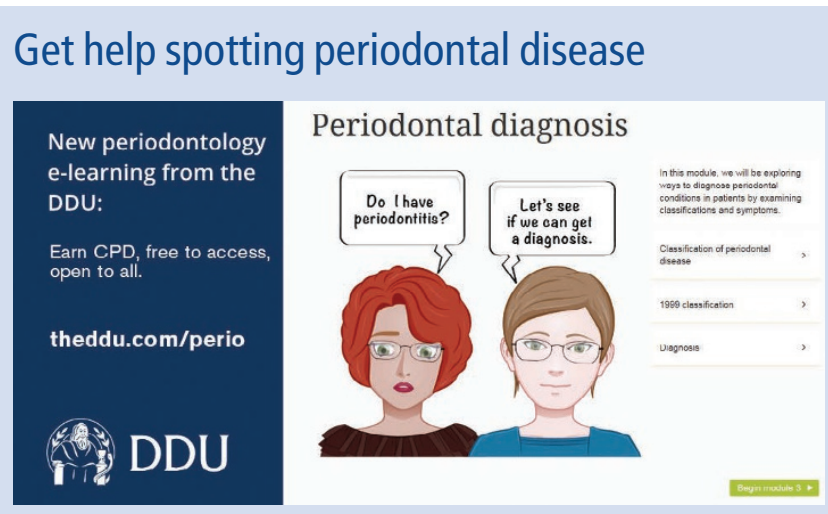

Dental professionals are being given help with the diagnosis and treatment of periodontal disease in the form of a new elearning module from the Dental Defence Union (DDU) and the British Society of Periodontology (BSP). Allegations of failure to diagnose or treat periodontal disease account for about $10 \%$ of claims notified to the DDU each year and some claims can reach $£ 220,000$ in compensation and legal costs.

The course, which has been co-written by the BSP and the $\mathrm{DDU}$, combines the expertise of both organisations on the clinical assessment, diagnosis and treatment of periodontitis, as well as the dento-legal aspects surrounding the condition.

Divided into six modules, the new online course is worth three hours of verifiable continuing professional development (CPD), and is free for any dental professional to complete. The CPD gained will also help professionals meet the new GDC CPD requirements, due to come into force in 2018 . The six modules are: Communication, Initial assessment part 1 , Initial assessment part 2, Classification of periodontal disease, Treatment part 1, and Treatment part 2.

The course covers areas such as taking a detailed history, getting consent, using the Basic Periodontal Examination effectively, assessing periodontal conditions, formulating treatment plans, and techniques for producing patient behaviour change. At the end of the course, participants will take part in an assessment to test their knowledge.

The elearning module can be accessed at: https://www.theddu.com/learn-and-develop/ free-cpd-modules-from-the-bsp-and-the-ddu.

\section{Implantology product solutions}

Henry Schein Dental has launched the DENTAL RATIO implant system with exclusive distribution rights in the UK. The new agreement further extends the company's range of solutions for the implantological daily routine.

Implantology is an integral part of

many dental treatment concepts.

In order to offer its customers

high-quality products in

this sector, Henry Schein

Dental will act as the

exclusive supplier of the

OKTAGON implant

system, including two
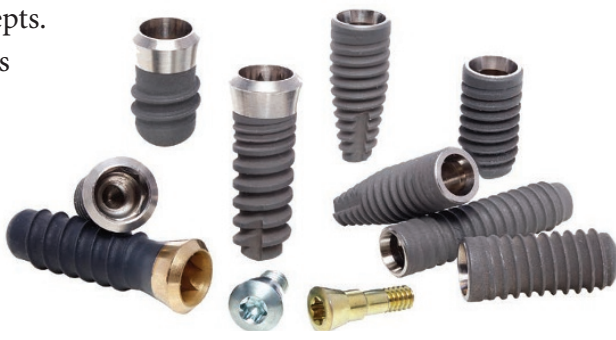

additional modern

implant lines from DRS International.

- ROX-CERA Cerid implant with ceramic coating: The OKTAGON ROX-CERA implant (bone and tissue level) is made of a grade- 5 titanium core and additionally ceramic coated, which supports the long-term stable osseointegration.

The enossal part of the implant is provided with a ceramic, opaque, biocompatible wear- and corrosion-protection layer. The oxides of zirconium are thermodynamically and biochemically stable. Friction corrosion is avoided, and the shear strength of the surface is increased compared to the pure surface.

The transgingival part of the tissue-level implant is coated with a spontaneously self-passivating, biochemically stable titaniumniobium-oxynitride layer. The high-level layer hardness protects against injuries caused by instruments. The smooth surface counteracts possible plaque formation

- BLT/bone level tapered implant

The OKTAGON BLT implant with its apical, conical shape can be helpful in unfavourable bone conditions. The BLT implant is characterised by a high primary stability in soft bone and fresh extraction sockets. The grade- 4 titanium implant is available in several diameters and lengths.

With the distribution of the OKTAGON implant system, Henry Schein Dental underlines its claim to provide a wide range of functional and high-quality products.

\title{
Perfectly match surrounding teeth
}

TAUB Products, a long-time manufacturer of dental laboratory and restorative products, has announced the reintroduction of Minute Stains, ultrathin acrylic liquids in a variety of colours that allow natural characterisation of milled PMMA provisionals, temporaries, composite teeth, and denture teeth. By mixing and layering colors, Minute Stains give an unlimited variation of colour options to perfectly match the surrounding teeth. Each application of stain air-dries in 15 seconds, saving patient chair time.

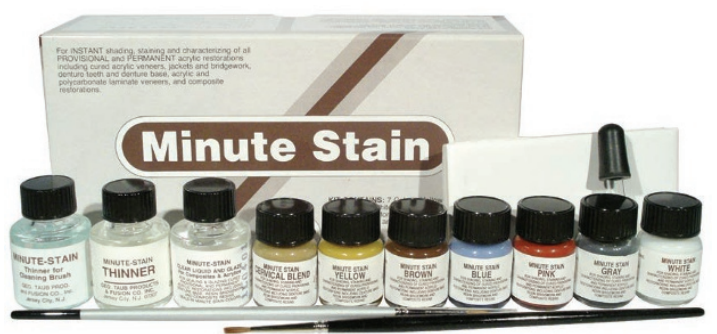

TAUB Minute Stains are available in two kit options: the three-colour kit contains a cervical blend, yellow, and grey colours, and the seven-colour kit has additional colours of blue, brown, white, and pink.

TAUB Products is celebrating its $65^{\text {th }}$ year in business. TAUB provides innovative, high-quality solutions for dental professionals. For more information on TAUB and its products, visit www.taubdental.com. 